\title{
ON POOLED OLS AND PANEL REGRESSION MODELS FOR ASSESSING THE CONTRIBUTIONS OF ELECTRONIC PAYMENT SYSTEM ON COMMERCIAL BANKS PROFITABILITY
}

\author{
KAYODE S. ADEKEYE ${ }^{1,2}$, KELVIN E. IGWE ${ }^{2}$ \\ and OLANIYI M. OLAYIWOLA ${ }^{3}$ \\ ${ }^{1}$ Department of Mathematical Sciences \\ Redeemer's University \\ Ede
}

Nigeria

e-mail: adekeyek@run.edu.ng

2Department of Mathematics

University of Lagos

Nigeria

${ }^{3}$ Department of Statistics

Federal University of Agriculture

Abeokuta

Nigeria

2020 Mathematics Subject Classification: 62-07, 62P20, 62 N02.

Keywords and phrases: random effect, fixed effect, electronic payment system, pooled OLS, panel regression.

Received May 4, 2021; Revised June 10, 2021

This work is licensed under the Creative Commons Attribution International License (CC BY 3.0).

http://creativecommons.org/licenses/by/3.0/deed.en_US

Open Access (cc) ()




\begin{abstract}
This study examined the impact of electronic payment system on the profitability of commercial banks in Nigeria. Pooled OLS and Panel regression models were fitted on the data extracted from the banks' annual reports, Nigerian interbank settlement scheme, and central bank of Nigeria website. The assessment of the contribution of the various electronic payment systems considered were measured using Breusch and Pagan Lagrangian Multiplier (LM) Test, the Hausman Test, Stationarity Test, The Schwarz Criterion, and the Akaike Information Criterion. Results obtained showed that the random effect model was more appropriate than the fixed effect model for all the electronic payment systems considered in this study. Furthermore, it was discovered that there exists a positive relationship between the electronic payment systems and profitability of the commercial banks in Nigeria.
\end{abstract}

\title{
1. Introduction
}

In developing economy like Nigeria, financial sector developments have been accompanied by structural and institutional changes because of its crucial role in the economic development of the nation. In pursuance of its core mandate, the Central Bank of Nigeria (CBN) had engaged in series of reforms aimed at making the financial system formidable and enhancing the overall economic growth of Nigeria (Ajayi [3]). The development of the financial sector has been a major growth driver in all economies, especially in emerging economies. Part of the financial innovations in the sector in recent times is the electronic payment system (Mustapha [10]). The Nigerian financial sector is undoubtedly the most important in the political-economic systems; because it provides the necessary lubricant that keeps the wheel of the economy turning and it is an engine for economic growth.

Activities of the Nigerian financial sector depends largely on deposit money banks. Hence, bank performance is crucial to financial sector development. The evolution of electronic banking platforms/technologies came to existence in 2012 , following the directives of the central bank of Nigeria to promote cashless systems. Alternative payments refer to 
ON POOLED OLS AND PANEL REGRESSION MODELS ...

payment methods that are used as an alternative to credit card payments. Most alternative payment methods address a domestic economy or have been specifically developed for electronic commerce and the payment systems are generally supported and operated by local banks. Each alternative payment method has its own unique application and settlement process language and currency support. All these constitute the culture of the payment system, and they are subject to domestic rules and regulations with their specific uncertainty. The electronic payment instruments consist of the Automatic Teller Machine (ATM), Point on Sale (POS), mobile money, and internet banking, among others. Payment activities on these channels are sponsored by deposit money banks in Nigeria with support from FinTech companies such as Visa international, Master Card Incorporation, Interswitch company etc. End users use the card to facilitate transactions on ATM and POS terminals. The adoption was quite impressive, as it grew from inception (Mustapha [10]).

Alternative payments have revolutionized the payments landscape in the economy. Although cash has remained the dominant payment instrument, its use has been declining as an increase in the number of EFTPOS terminals in retail payments has significantly expanded the use of debit and credit cards. Debit cards facilitate electronic transfers directly from customers' deposit accounts to the merchants account while credit cards fund payments by way of loans granted by the issuing financial institution. The innovation of these alternative payment systems has greatly influenced the phase of the banking sector. ATM and POS transactions used as a proxy for the adoption of cashless policy had revealed to have significantly influenced commercial bank profitability in Nigeria (Akara and Asekome [4]).

Several researches have been carried out to find the extent to which alternative payment system has impacted on banks using both qualitative and quantitative data. The widely used e-payment technologies in Nigeria 
are ATM, POS Technology, Mobile Money Transfer (MMT) Technology, and Online Money Payment (WEB) Technology (Mustapha [10]). Akara and Asekome [4] examined the effects of the adoption of cashless policy on the profitability performance of commercial banks in Nigeria by using ATM and POS as proxy for the adoption of cashless policy and ROA and ROE as proxy for profitability. Milind [7] reported that transaction with internet banking does not have a significant impact on performance and risk profile. Abaenewe et al. [1] analysed the effect of e-banking on bank performance in Nigeria and observed that e-banking has positively and significantly impacted on return on equity while e-banking did not impact significantly on return on assets. Ibukunle and James [6] claimed that e-banking has led to increased customer satisfaction, improved operational efficiency, reduced transaction time, better competitive edge, reduced running cost, and ushered in swift response in service delivery. Osazevbaru et al. [8] examined the impact of cashless policy on the profitability of Nigerian banks, against the backdrop that banks in a cash based economy are known for their huge profits even in the face of associated high cost of operations.

This study focus is on the panel regression modelling strategy in investigating how $\mathrm{CBN}$ alternative payment system has impacted on the profitability of commercial banks in Nigeria. The ROA and ROE were used as proxies for the profitability of the selected banks, and the performance of pooled OLS and panel regression models were compared.

\section{Pooled OLS and Panel Regression Model}

\subsection{The pooled OLS model}

The pooled time series and cross-section with both the time dimension and the cross-section dimension are explicitly expressed as:

$$
y_{i t}=X_{i t} \beta+\omega_{i t}, \quad i=1, \ldots, N ; t=1, \ldots, T,
$$


where

$$
X_{i t}=\left[x_{1 i t} \ldots x_{k i t}\right]_{(k \times 1)} \text { and } \beta=\left[\begin{array}{c}
\beta_{1} \\
\ldots \\
\beta_{k}
\end{array}\right]_{(1 \times k)} \text {. }
$$

A compact matrix representation for individual entities is as follows:

$$
y_{i}=X_{i} \beta+\omega_{i}, \ldots, \quad i=1, \ldots, N,
$$

where

$$
y_{i}=\left[\begin{array}{c}
y_{i 1} \\
\cdots \\
y_{i T}
\end{array}\right]_{(T \times 1)}, X_{i}=\left[\begin{array}{c}
X_{i 1} \\
\ldots \\
X_{i T}
\end{array}\right]=\left[\begin{array}{ccc}
X_{1 i 1} & \ldots & X_{K i 1} \\
\ldots & \ldots & \ldots \\
X_{1 i T} & \ldots & X_{K i T}
\end{array}\right]_{(T \times K)},
$$

and

$$
\omega_{i}=\left[\begin{array}{c}
\omega_{i 1} \\
\cdots \\
\omega_{i T}
\end{array}\right]_{(T \times 1)}
$$

For any individual entity, $y_{i}$ is a $(T \times 1)$ vector for $T$ observations of the dependent variable, $X_{i}$ is a $(T \times K)$ matrix of independent variables or regressors with $K$ being the number of independent variables, and $\beta$ is a $(K \times 1)$ vector of coefficients.

A compact matrix representation for the panel is

$$
y=X \beta+\omega,
$$

where

$$
y_{i}=\left[\begin{array}{c}
y_{i 1} \\
\ldots \\
y_{i T}
\end{array}\right]_{((T \times N) \times 1)}, X_{i}=\left[\begin{array}{c}
X_{i 1} \\
\cdots \\
X_{i T}
\end{array}\right]_{((T \times N) \times K)} \text {, and } \omega_{i}=\left[\begin{array}{c}
\omega_{i 1} \\
\ldots \\
\omega_{i T}
\end{array}\right]_{((T \times N) \times 1)} .
$$




\subsection{The panel regression model}

Panel data refer to data sets consisting of cross-sectional observations over time, or pooled cross-section and time series data (Peijie [9]). "Panel Data" is a set of data obtained by observation of the characteristics of a variety of units (cross-sectional variables) over time (Ahn et al. [2]). Panel data set have both cross-sectional and time-series dimensions. The size of the time series is formed by monitoring the same cross-section units during a given period. When each subject (cross-sectional unit) has the same number of observations, this type of panel is called a balanced panel data set. If some subjects have different number of observations, this situation is known as the unbalanced data case (Wooldridge [11]). Panel data provide more informative data, more variability, more degrees of freedom, more efficiency, and less co-linearity among the variables (Baltagi [5]). Panel regression model can either be of random effect model or fixed effect model.

\subsubsection{Random effects model with individual effects}

The random effect model of the panel regression model is given by

$$
\omega_{i t}=\mu_{i}+\varepsilon_{i t},
$$

where $\mu_{i}$ is a random variable. The assumption of the model are $E\left(\mu_{i}\right)=0$,

$$
\operatorname{Var}\left(\mu_{i}\right)=\sigma_{\mu}^{2}, \operatorname{Cov}\left(\mu_{i}, X_{i t}\right)=0, \operatorname{Cov}\left(\mu_{i t}, \varepsilon_{i t}\right)=0, E\left(\varepsilon_{i t}\right)=0, \operatorname{Var}\left(\varepsilon_{i t}\right)=\sigma_{\mu}^{2} ;
$$

and $\varepsilon_{i t}$ is pure residuals uncorrelated with each other and uncorrelated with independent variables.

A compact matrix representation for the panel data model with random individual effects is

$$
y=X \beta+\mu+\varepsilon,
$$


where

$$
\mu=\left[\begin{array}{c}
\mu_{1} \\
\cdots \\
\mu_{N}
\end{array}\right]_{((T \times N) \times 1)}, \varepsilon=\left[\begin{array}{c}
\varepsilon_{1} \\
\cdots \\
\varepsilon_{N}
\end{array}\right]_{((T \times N) \times 1)}, \mu_{i}=\left[\begin{array}{c}
\mu_{i} \\
\ldots \\
\mu_{i}
\end{array}\right]_{(T \times 1)},
$$

and

$$
\varepsilon_{i}=\left[\begin{array}{c}
\varepsilon_{i 1} \\
\cdots \\
\varepsilon_{i T}
\end{array}\right]_{(T \times 1)}
$$

Taking into considering the non-zero within entity covariance or nonzero off-diagonal elements of the entity covariance matrix, and the heteroskedasticity arising from the heterogeneity of effects, its random effects estimators can be derived by the GLS as follows:

$$
\begin{aligned}
b & =X^{\prime} \sum^{-1} X^{-1} X^{\prime} \sum^{-1} y+\left(X^{\prime} \sum^{-1} X\right)^{-1} X^{\prime} \sum^{-1}(\mu+\varepsilon) \\
& =\beta+\left(X^{\prime} \sum^{-1} X\right)^{-1} X^{\prime} \sum^{-1}(\mu+\varepsilon) .
\end{aligned}
$$

With the covariance matrix for the panel being

$$
\sum=\left[\begin{array}{lll}
\sum_{1} & & \\
& \sum_{\ldots} & \\
& & \sum_{N}
\end{array}\right]_{[(T \times N) \times(T \times N)]},
$$


and the within entity covariance matrix being

$$
\sum_{i}=\left[\begin{array}{cccc}
\sigma_{\mu}^{2}+\sigma_{\varepsilon}^{2} & \sigma_{\mu}^{2} & \ldots & \sigma_{\mu}^{2} \\
\sigma_{\mu}^{2} & \sigma_{\mu}^{2}+\sigma_{\varepsilon}^{2} & \ldots & \sigma_{\mu}^{2} \\
\ldots \sigma_{\mu}^{2} & \ldots \sigma_{\mu}^{2} & \ldots & \sigma_{\mu}^{2}+\sigma_{\varepsilon}^{2}
\end{array}\right]_{(T \times T)} .
$$

Normal distributions are assumed for the residual $\varepsilon_{i t}$, the maximum likelihood procedure was applied to obtain random effects estimators of parameters. The corresponding likelihood function $(L)$ and the log likelihood function $(L L)$ are presents as follows:

$$
\begin{aligned}
L & =(2 \pi)^{-(N \times T) / 2}\left(\left|\sum^{-1}\right|\right)^{1 / 2} \exp \left(-\left[(y-X \beta)^{\prime} \sum^{-1}(y-X \beta) / 2\right]\right) \\
& =\prod_{i=1}^{N}(2 \pi)^{-T / 2}\left(\left|\sum_{i}^{-1}\right|\right)^{1 / 2} \exp \left(-\left[\left(y_{i}-X_{i} \beta\right)^{\prime} \sum_{i}^{-1}\left(y_{i}-X_{i} \beta\right) / 2\right]\right)
\end{aligned}
$$

and

$$
\begin{aligned}
L L & =\operatorname{Ln}\left\{(2 \pi)^{-(N \times T) / 2}\left(\left|\sum^{-1}\right|\right)^{1 / 2} \exp \left(-\left[(y-X \beta)^{\prime} \sum^{-1}(y-X \beta) / 2\right]\right)\right\} \\
& =\frac{1}{2}\left[-N \times T \times \operatorname{Ln}(2 \pi)+\operatorname{Ln}\left(\left|\sum_{i}^{-1}\right|\right)-(y-X \beta)^{\prime} \sum^{-1}(y-X \beta)\right] \\
& =\frac{1}{2} \sum_{2}^{1}\left[-T \times \operatorname{Ln}(2 \pi)+\operatorname{Ln}\left(\left|\sum_{i}^{-1}\right|\right)-\left(y_{i}-X_{i} \beta\right)^{\prime} \sum_{i}^{-1}\left(y_{i}-X_{i} \beta\right)\right] .
\end{aligned}
$$




\subsubsection{Random effects model with individual and time effects}

On introducing the time effect on the model presented in Equation (4), the random effect model with individual and time effects is

$$
\omega_{i t}=\mu_{i}+\tau_{t}+\varepsilon_{i t}
$$

$\tau_{t}$ is a random variable with $E\left(\tau_{t}\right)=0, \operatorname{Var}\left(\tau_{t}\right)=\sigma_{\mu}^{2}, \operatorname{Cov}\left(\tau_{t}, X_{i t}\right)=0$, $\operatorname{Cov}\left(\tau_{t}, \varepsilon_{i t}\right)=0, E\left(\varepsilon_{i t}\right)=0, \operatorname{Var}\left(\varepsilon_{i t}\right)=\sigma_{\mu}^{2}$, and $\varepsilon_{i t}$ is pure residuals uncorrelated with each other and uncorrelated with independent variables. A compact matrix of Equation (11) is

$$
y=X \beta+\mu+\tau+\varepsilon,
$$

where

$$
\tau=\left[\begin{array}{c}
\tau_{1} \\
\ldots \\
\tau_{N}
\end{array}\right]_{((T \times N) \times 1)}, \varepsilon=\left[\begin{array}{c}
\varepsilon_{1} \\
\ldots \\
\varepsilon_{N}
\end{array}\right]_{((T \times N) \times 1)}, \mu_{i}=\left[\begin{array}{c}
\tau_{1} \\
\ldots \\
\tau_{T}
\end{array}\right]_{(T \times 1)}, \text { and } \varepsilon_{i}=\left[\begin{array}{c}
\varepsilon_{i 1} \\
\ldots \\
\varepsilon_{i T}
\end{array}\right]_{(T \times 1)} \text {. }
$$

Taking into consideration the non-zero within entity covariance or nonzero off-diagonal element of the entity covariance matrix, and the heteroskedasticity arising from the heterogeneity of effects, its random effects estimators of $\beta, b$, was derived by the GLS as follows:

$$
\begin{aligned}
b & =X^{\prime} \sum^{-1} X^{-1} X^{\prime} \sum^{-1} y+\left(X^{\prime} \sum^{-1} X\right)^{-1} X^{\prime} \sum^{-1}(\mu+\tau+\varepsilon) \\
& =\beta+\left(X^{\prime} \sum^{-1} X\right)^{-1} X^{\prime} \sum^{-1}(\mu+\tau+\varepsilon) .
\end{aligned}
$$

With the covariance matrix for the panel being

$$
\sum=\left[\begin{array}{ccc}
\sum_{1} & \sum_{12} & \sum_{1 N} \\
\sum_{21} & \sum_{\ldots} & \\
\sum_{N 1} & \ldots & \sum_{N}
\end{array}\right]_{[(T \times N) \times(T \times N)]}
$$


where the within entity covariance matrix being

$$
\sum_{i}=\left[\begin{array}{cccc}
\sigma_{\mu}^{2}+\sigma_{\varepsilon}^{2} & \sigma_{\mu}^{2} & \ldots & \sigma_{\mu}^{2} \\
\sigma_{\mu}^{2} & \sigma_{\mu}^{2}+\sigma_{\varepsilon}^{2} & \ldots & \sigma_{\mu}^{2} \\
\ldots \sigma_{\mu}^{2} & \ldots \sigma_{\mu}^{2} & \ldots & \sigma_{\mu}^{2}+\sigma_{\varepsilon}^{2}
\end{array}\right]_{(T \times T)},
$$

and the between entities covariance matrix is

$$
\sum_{i j}=\left[\begin{array}{cccc}
\sigma_{\mu}^{2} & 0 & \cdots & 0 \\
0 & \sigma_{\mu}^{2} & \ldots & 0 \\
\ldots 0 & \cdots & \ldots & \sigma_{\mu}^{2}
\end{array}\right]_{(T \times T)} .
$$

With normally distributed residual $\varepsilon_{i t}$, the maximum likelihood procedure was applied. The corresponding likelihood function $(L)$ and the log likelihood function $(L L)$ are as follows:

$$
L=(2 \pi)^{-(N \times T) / 2}\left(\left|\sum^{-1}\right|\right)^{1 / 2} \exp \left(-\left[(y-X \beta)^{\prime} \sum^{-1}(y-X \beta) / 2\right]\right),
$$

and

$$
\begin{aligned}
L L & =\operatorname{Ln}\left\{(2 \pi)^{-(N \times T) / 2}\left(\left|\sum^{-1}\right|\right)^{1 / 2} \exp \left(-\left[(y-X \beta)^{\prime} \sum^{-1}(y-X \beta) / 2\right]\right)\right\} \\
& =\frac{1}{2}\left[-N \times T \times \operatorname{Ln}(2 \pi)+\operatorname{Ln}\left(\left|\sum_{i}^{-1}\right|\right)-(y-X \beta)^{\prime} \sum^{-1}(y-X \beta)\right] .
\end{aligned}
$$

Both fixed effects and random effects models was estimated by maximum likelihood method. 


\subsubsection{Fixed effects models with individual effects}

The fixed effects model assumes that

$$
\omega_{i t}=c_{i}+\varepsilon_{i t},
$$

where $c_{i}$ is individual-specify and time-invariant unobserved heterogeneity and is a constant for entity $I, \operatorname{Cov}\left(c_{i}, X_{i t}\right) \neq 0, \operatorname{Cov}\left(\varepsilon_{i t}, X_{i t}\right)=0$, $\operatorname{Var}\left(\varepsilon_{i t}\right)=\sigma_{t}^{2} ; \varepsilon_{i t}$ is pure residuals uncorrelated with each other and uncorrelated with independent variables. A compact matrix representation for the panel data model with fixed effects is

$$
y=c+X \beta+\varepsilon,
$$

where

$$
c=\left[\begin{array}{c}
c_{1} \\
\ldots \\
c_{N}
\end{array}\right]_{((T \times N) \times 1)}, \varepsilon=\left[\begin{array}{c}
\varepsilon_{1} \\
\ldots \\
\varepsilon_{N}
\end{array}\right]_{((T \times N) \times 1)}, c_{i}=\left[\begin{array}{c}
c_{i} \\
\ldots \\
c_{i}
\end{array}\right]_{(T \times 1)}, \text { and } \varepsilon_{i}=\left[\begin{array}{c}
\varepsilon_{i 1} \\
\ldots \\
\varepsilon_{i T}
\end{array}\right]_{(T \times 1)} .
$$

Fixed effects models cannot be readily estimated by the OLS. There are few approaches that augment the OLS, such as resorting to dummies, applying first differencing over time, and performing the within transformation.

The dummy variable least squares (DVLS), let $1_{i}$ be a $(T \times 1)$ vector of $I$ 's, $I$ be a $(T \times N) \times N)$ matrix of $1_{i}$ and 0 , and $\delta$ be a $(N \times 1)$ vector of dummy coefficients

$$
I_{t}=\left[\begin{array}{l}
1 \\
\cdots \\
I
\end{array}\right]_{(T \times 1)}, I=\left[\begin{array}{ccc}
I_{1} & 0 & 0 \\
\cdots & \cdots & \cdots \\
0 & 0 & I_{N}
\end{array}\right]_{((T \times N) \times N)}, \delta=\left[\begin{array}{c}
\delta_{1} \\
\ldots \\
\delta_{N}
\end{array}\right]_{(N \times 1)} .
$$


Then the rearranged representation of Equation (18) was estimated by the OLS, which produced unbiased fixed effects estimators:

$$
y=[X, I]\left[\begin{array}{l}
\beta \\
\delta
\end{array}\right]+\varepsilon .
$$

It follows that, $b$ and $d$, the DVLS estimators of $\beta$ and $\delta$, are

$$
\begin{aligned}
{\left[\begin{array}{l}
b \\
d
\end{array}\right] } & =\left([X, I]^{\prime}[X, I]\right)^{-1}[X, I]^{\prime} y+\left([X, I]^{\prime}[X, I]\right)^{-1}[X, I]^{\prime} \varepsilon \\
& =\left[\begin{array}{l}
b \\
d
\end{array}\right]+\left([X, I]^{\prime}[X, I]\right)^{-1}[X, I]^{\prime} \varepsilon .
\end{aligned}
$$

If $\delta_{1}=\delta_{2}=\cdots=\delta_{N}=\delta$, then $\delta$ is simply a common intercept for all the entities within the panel or for the whole panel. So, restrictions can be imposed on the estimated dummy coefficients. If the restrictions of $\delta_{1}=\delta_{2}=\cdots=\delta_{N}=\delta$, are rejected, the panel data model is regarded to possess the features of fixed effects and there $\delta_{1}=\delta_{2}=\cdots=\delta_{N}=\delta$, are rejected, then there are no fixed effects variations in intercepts and the whole panel has just one common intercept.

When the residual, $\varepsilon_{i t}$, is distributed normally, the maximum likelihood procedure can be applied to obtain fixed effects estimators of the parameters. The likelihood function $(L)$ and the log likelihood function $(L L)$ are as follows:

$$
\begin{aligned}
L & =\prod_{i=1}^{N} \varnothing\left(y_{i}-X_{I} \beta-I_{I} \delta\right)=\prod_{i=1}^{N} \frac{1}{\sigma_{\varepsilon}}\left(\frac{y_{i}-X_{I} \beta-I_{I} \delta}{\sigma_{\varepsilon}}\right) \\
& =\prod_{i=1}^{N}\left(2 \pi \sigma_{\varepsilon}^{2}\right)^{-T / 2} \exp \left(-\left[\frac{\left(y_{i}-X_{I} \beta-I_{I} \delta\right)^{\prime}\left(y_{i}-X_{I} \beta-I_{I} \delta\right)}{2 \sigma_{\varepsilon}^{2}}\right]\right),
\end{aligned}
$$


and

$$
\begin{aligned}
L L & =\sum_{i=1}^{N} \operatorname{Ln}\left\{\frac{1}{\sigma_{\varepsilon}} \varnothing\left(\frac{y_{i}-X_{I} \beta-I_{I} \delta}{\sigma_{\varepsilon}}\right)\right\} \\
& =\sum_{i=1}^{N} \operatorname{Ln}=\left(2 \pi \sigma_{\varepsilon}^{2}\right)^{-(N \times T) / 2} \exp \left(-\left[\frac{\left(y_{i}-X_{I} \beta-I_{I} \delta\right)^{\prime}\left(y_{i}-X_{I} \beta-I_{I} \delta\right)}{2 \sigma_{\varepsilon}^{2}}\right]\right) \\
& =-\frac{N \times T}{2} \operatorname{Ln}\left(2 \pi \sigma_{\varepsilon}^{2}\right)-\frac{1}{2 \sigma_{\varepsilon}^{2}} \sum_{i=1}^{N}\left(y_{i}-X_{I} \beta-I_{I} \delta\right)^{\prime}\left(y_{i}-X_{I} \beta-I_{I} \delta\right),
\end{aligned}
$$

where $\varnothing(z)$ is the density function of the normal distribution.

\subsubsection{Fixed effects models with individual effects and time effects}

Considering both individual effects and time effects in the fixed effects panel data model presented as follows:

$$
y=c+h+X \beta+\varepsilon
$$

where $h=\left[\begin{array}{c}h_{j} \\ \ldots \\ h_{T}\end{array}\right]_{((T \times N) \times 1)}, h_{T}=\left[\begin{array}{c}h_{j} \\ \ldots \\ h_{T}\end{array}\right]_{(T \times N)}$ and the rest is the same as in

Equation (18).

The dummy variable approach, the DVLS, was applied to both individual effects and time effects in the panel data model. However, if we use one dummy for one entity for all $N$ entities and one dummy for one time for all $T$ periods, then both individual dummies and time dummies sum to one. Thus, we must remove one dummy, either time dummy or individual dummy, from estimation. We remove one time dummy for the first period, so the first period indicated that the value of the dependent variable is greater by the extent of $h_{3}$ relative to the base period, other things being equal. This dummy variable representation of the panel data 
model, incorporating both individual effects and time effects, was express by the following equation:

$$
y=[X, J]\left[\begin{array}{l}
\beta \\
\delta \\
\xi
\end{array}\right]+\varepsilon,
$$

where

$$
\begin{aligned}
& J=\left[\begin{array}{ccccc}
I_{1} & 0 & \ldots & 0 & J_{1} \\
0 & \ldots & 0 & I_{N} & J_{T[(T \times N) \times(N \times T)]}
\end{array}\right], I_{i}=\left[\begin{array}{c}
I \\
\cdots \\
I
\end{array}\right]_{(T \times 1)}, \\
& J_{i}=\left[\begin{array}{ccc}
0 & \cdots & 0 \\
1 & \cdots & 0 \\
0 & \cdots & 1
\end{array}\right]_{[T \times(T-1)]} \quad \delta=\left[\begin{array}{c}
\delta_{1} \\
\cdots \\
\delta_{N}
\end{array}\right]_{(N \times 1)}, \text { and } \xi=\left[\begin{array}{c}
\xi_{1} \\
\cdots \\
\xi_{N}
\end{array}\right]_{[T \times(T-1)]} .
\end{aligned}
$$

Then, $b, d$ and $z$, the DVLS estimators of $\beta, \delta$ and $\xi$, and was derived from the following operations:

$$
\begin{aligned}
{\left[\begin{array}{l}
b \\
d \\
z
\end{array}\right] } & =\left([X, J]^{\prime}[X, J]\right)^{-1}[X, J]^{\prime} y+\left([X, J]^{\prime}[X, J]\right)^{-1}[X, J]^{\prime} \varepsilon \\
& =\left[\begin{array}{l}
\beta \\
\delta \\
\xi
\end{array}\right]+\left([X, J]^{\prime}[X, J]\right)^{-1}[X, J]^{\prime} \varepsilon .
\end{aligned}
$$

When the residual, $\varepsilon_{i j}$, is assumed to be normally distributed, the maximum likelihood procedure can be applied to obtain fixed effects parameter estimators. The likelihood function $(L)$ and the log likelihood function $(L L)$ are described by the following two representations respectively: 


$$
\begin{aligned}
L & =\phi\left(y-X \beta-J\left(\begin{array}{l}
\delta \\
\xi
\end{array}\right)\right)=\frac{1}{\sigma_{\varepsilon}} \phi\left(\frac{y-X \beta-J\left(\begin{array}{l}
\delta \\
\xi
\end{array}\right)}{\sigma_{\varepsilon}}\right) \\
& =\left(2 \pi \sigma_{\varepsilon}^{2}\right)^{-(N \times T) / 2} \exp \left(\left[y-X \beta-J\left(\begin{array}{l}
\delta \\
\xi
\end{array}\right)\right]^{\prime}\left[y-X \beta-J\left(\begin{array}{l}
\delta \\
\xi
\end{array}\right)\right] / 2 \sigma_{\varepsilon}^{2}\right),
\end{aligned}
$$

and

$$
\begin{aligned}
L L & =\operatorname{Ln}\left\{\frac{1}{\sigma_{\varepsilon}} \phi\left(\frac{y-X \beta-J\left(\begin{array}{l}
\delta \\
\xi
\end{array}\right)}{\sigma_{\varepsilon}}\right)\right\} \\
& \left.=\operatorname{Ln}\left\{\left(2 \pi \sigma_{\varepsilon}^{2}\right)^{-(N \times T) / 2} \exp \left(-\left[y-X \beta-J\left(\begin{array}{l}
\delta \\
\xi
\end{array}\right)\right]^{\prime} \times\left[y-X \beta-J\left(\begin{array}{l}
\delta \\
\xi
\end{array}\right)\right] / 2 \sigma_{\varepsilon}^{2}\right)\right)\right\} .
\end{aligned}
$$

\section{Model Selection Criterial}

\subsection{The Breusch and Pagan Lagrangian multiplier (LM) test}

The Breusch and Pagan Lagrangian multiplier test was run on the random effect model to choose between the pooled OLS model and regression model. The LM test was run based on the formulation.

$$
L M_{u}=\frac{n T}{2(T-1)}\left[\frac{\sum\left(\sum e_{i t}\right)^{2}}{\sum \sum e_{i t}^{2}}-1\right]^{2}=\frac{n T}{2(T-1)}\left[\frac{\sum(T) e_{i t}{ }^{2}}{\sum \sum e_{i t}^{2}}-1\right]^{2} \sim \chi^{2}(1)
$$




\subsection{The Hausman (H) test}

The Hausman test was run to choose between random effect model and fixed effect model based on the specification.

$$
H=\left(\hat{\beta}_{F E}-\hat{\beta}_{R E}\right)^{\prime}\left[\left(V\left(\hat{\beta}_{F E}\right)-V\left(\hat{\beta}_{F E}\right)(-1)\right)\right]\left(\hat{\beta}_{F E}-\hat{\beta}_{R E}\right) .
$$

\subsection{The Akaike information criterion}

The Akaike Information Criterion (AIC) used for assessing the goodness of fit is

$$
A I C=\ln \left(\frac{\sum_{i=1}^{n} \ell_{i}^{2}}{n}\right)+\frac{2 k}{n} .
$$

The criterion is to include an extra variable only if it decreases the AIC.

The AIC depends on $\sum_{i=1}^{n} \ell_{i}^{2}$ and $K$ (number of parameters to be estimated). However, a fall in $\sum_{i=1}^{n} \ell_{i}^{2}$ that occurs when an extra explanatory variable is included may not necessarily lead to a fall in the AIC. The extra variable means an increase in $K$, and this increase AIC.

\subsection{The Schwarz criterion}

This method works like the AIC except that it has additional components with a view to improving on it. The SC is given as:

$$
S C=\ln \left(\frac{\sum_{i=1}^{n} \ell_{i}^{2}}{n}\right)+\frac{k}{n} \ln (n) .
$$




\section{Discussion of Results}

Data used in this study were extracted from profitability of commercial banks at 2 levels (Return on Assets (ROA) and Return on Equity (ROE)) from 2014 to 2018. Fifteen (15) banks listed on the Nigerian Stock Exchange have the required information paramount to this study and 3 out of these listed banks (Zenith Bank, Wema bank and Keystone bank) were randomly selected.

ROE and ROA are two measures for commercial banks' profitability. The information was extracted on each bank's Net Income (profit for the year), Total Assets, and Total Equity (contributions by the bank's shareholders). The ROE and ROA were calculated as specified below:

$$
\mathrm{ROE}=\frac{\text { Net Income }}{\text { Total Equity Capital }}
$$

and

$$
\text { ROA }=\frac{\text { Net Income }}{\text { Total Assest }}
$$

The pooled OLS model and the panel regression model were used to find out the electronic payment system that influenced the profitability of commercial banks.

The summary statistics of each of the variable used in this study are presented in Table 1 (see Appendix). The mean values of the variables reveal that they all have positive averages over the study period except for ROA and ROE, and the standard deviation shows a non-volatile effect of the studied variables. The results in Table 2 in the Appendix revealed the order of integration and the significance level of the variables of the model. It was observed that the ATM, POS, and WEB contributed significantly to the profitability of commercial banks (see Table 3). The coefficient of determination for the pooled OLS regression model and random effect regression model are $16 \%$ and $18 \%$, respectively. Thus, we 
can comfortably infer that there are some other bank activities apart from ATM, POS, and WEB that contribute significantly to the profitability of commercial banks.

The Lagrange Multiplier (LM) tests for random effects revealed that there is panel effect (i.e., random effect is appropriate) as the $p$-value is less than 0.05. Also, the pooled random effect regression model was found more appropriate as the Hausman test revealed that the random effect regression is more adequate compared to the fixed effect for the return of asset variable. On using the Return on Equity (ROE), the R squared for both pooled OLS and random effect models is $18.22 \%$ (see Table 4). Furthermore, the $p$-value for ATM and POS show that they both have significance effect on the ROE. However, the EMB and WEB have relatively non-significant effect on the ROE (see Table 4).

The heterogeneity test revealed that the pooled OLS regression is adequate and consistent. The Lagrange Multiplier (LM) tests for random effects revealed that there is panel effect (i.e., random effect is appropriate) with a $p$-value of 0 . The pooled random effect regression model was found more appropriate as the Hausman test revealed that the random effect regression is more adequate compared to the fixed effect when ROE was used as a proxy for profitability.

\section{Conclusion}

There is a positive relationship between CBN alternative payment system and profitability. Both pooled OLS and panel regression models are efficient for assessing impact of Automated Teller Machine (ATM), Electronic Mobile Banking (EMB), Point of Sale (POS) and Internet Banking (WEB) on profitability of the commercial banks in Nigeria. The models revealed that there are some other bank activities that contribute more to the profitability of the commercial banks in Nigeria apart from Automated Teller Machine (ATM), Electronic Mobile Banking (EMB), Point of Sale (POS), and Internet Banking (WEB). 


\section{References}

[1] Z. C. Abaenewe, O. M. Ogbulu and M. O. Ndugbu, Electronic banking and bank performance in Nigeria, West African Journal of Industrial \& Academic Research 6(1) (2013), 171-187.

[2] S. C. Ahn, Y. H. Lee and P. Schmidt, GMM estimation of linear panel data models with time-varying individual effects, Journal of Econometrics 101(2) (2001), 219-255.

DOI: https://doi.org/10.1016/S0304-4076(00)00083-X

[3] L. B. Ajayi, Effect of cashless monetary policy on Nigerian banking industry: Issues, prospects and challenges, International Journal of Business and Finance Management Research 2 (2014), 29-41.

[4] C. K. Akara and M. O. Asekome, Cashless policy and commercial banks' profitability in Nigeria, Advances in Social Sciences Research Journal 5(3) (2018), 395-406.

DOI: https://doi.org/10.14738/assrj.53.4262

[5] B. H. Baltagi, Econometric Analysis of Panel Data, 4th Edition, John Wiley \& Sons Ltd., 2010.

[6] F. Ibukunle and O. James, Impact of information technology on Nigeria banking industry: A case study of Skye Bank, International Journal of Computing Academic Research 1(1) (2012), 25-35.

[7] S. Milind, The impact of internet banking on performance and risk profile: Evidence from Australian credit unions, Journal of Banking Regulation 6(2) (2005), 163-174.

DOI: https://doi.org/10.1057/palgrave.jbr.2340189

[8] H. O. Osazevbaru, E. J. Sakpaide and R. O. Ibubune, Cashless policy and banks' profitability in Nigeria, European Journal of Accounting and Auditing and Finance Research 2(10) (2014), 1-12.

[9] W. Peijie, Financial Econometrics, Second Edition, Milton Park, Abingdon, Oxon, 2009.

[10] Saidi A. Mustapha, E-payment technology effect on bank performance in emerging economies-evidence from Nigeria, Journal of Open Innovation: Technology, Market, and Complexity 4(4) (2018); Article 43.

DOI: https://doi.org/10.3390/joitmc4040043

[11] J. M. Wooldridge, Introductory Econometrics, 4th Edition, South Western Cengage Learning, Canada, 2009. 


\section{Appendix}

Table 1. Descriptive statistics

\begin{tabular}{|c|c|c|c|c|c|c|c|}
\hline & $\mathrm{N}$ & Minimum & Maximum & Mean & Std. deviation & Skewness & Kurtosis \\
\hline LogROA & 60 & -2.92 & 1.94 & -1.1980 & 1.41415 & .748 & -.889 \\
\hline LogROE & 60 & -2.03 & 2.84 & -.3288 & 1.43426 & .862 & -.741 \\
\hline $\operatorname{logATM}$ & 60 & 9.16 & 12.44 & 10.8004 & .88797 & -.404 & -1.055 \\
\hline LogEMB & 60 & 8.48 & 11.52 & 9.9165 & .77831 & .213 & -.637 \\
\hline LogPOS & 60 & 9.36 & 11.57 & 10.3190 & .50062 & -.047 & -.663 \\
\hline LogWEB & 60 & 8.44 & 10.80 & 9.6348 & .57707 & -.049 & -.619 \\
\hline
\end{tabular}

Table 2. Result for stationarity test

\begin{tabular}{|l|c|c|c|}
\hline Variable & ADF- Fisher Chi-square & Prob. $^{* *}$ & Lag \\
\hline ROA & 32.8483 & 0.0000 & 1 \\
\hline ROE & 29.9197 & 0.0000 & 1 \\
\hline ATM & 10.5941 & 0.1018 & 1 \\
\hline EBM & 33.6753 & 0.0000 & 1 \\
\hline POS & 0.60270 & 0.9964 & 1 \\
\hline WEB & 22.2015 & 0.0011 & 1 \\
\hline
\end{tabular}

Table 3. Pooled OLS model and random effect model of ROA

\begin{tabular}{|l|l|l|l|l|}
\hline \multicolumn{1}{|c|}{ ROA } & \multicolumn{2}{c|}{ Pooled OLS } & \multicolumn{2}{c|}{ Random effect } \\
\hline & Coefficient & $\mathrm{P}>\mathrm{t}$ & Coefficient & $\mathrm{P}>\mathrm{t}$ \\
\hline CONSTANT & 13.51796 & $0.0000 * * *$ & 13.51796 & $0.0000 * * *$ \\
\hline ATM & 2.108540 & $0.0251 * * *$ & 2.430541 & $0.0000 * * *$ \\
\hline EBM & 1.887026 & 0.0511 & 2.047033 & $0.0485 * * *$ \\
\hline POS & 2.475686 & $0.0431 * * *$ & 1.475346 & $0.0017 * * *$ \\
\hline WEB & 1.475586 & $0.0174 * * *$ & 2.026569 & $0.0137 * * *$ \\
\hline R-squared & 0.160145 & & 0.180195 & \\
\hline F-statistic & 6.714318 & & 7.671438 & \\
\hline Prob(F-statistic) & 0.000000 & & 0.000000 & \\
\hline
\end{tabular}


ON POOLED OLS AND PANEL REGRESSION MODELS ...

Table 4. Pooled OLS model and random effect model of ROE

\begin{tabular}{|l|l|l|l|l|}
\hline \multicolumn{1}{|c|}{ ROA } & \multicolumn{2}{c|}{ Pooled OLS } & \multicolumn{1}{c|}{ Random effect } \\
\hline & Coefficient & $\mathrm{P}>\mathrm{t}$ & Coefficient & $\mathrm{P}>\mathrm{t}$ \\
\hline CONSTANT & 15.62775 & $0.0000 * * * *$ & 15.62775 & $0.0000 * * *$ \\
\hline ATM & 1.044023 & $0.0014 * * *$ & 1.044023 & $0.0029 * * *$ \\
\hline EBM & 1.250700 & 0.1032 & 1.250700 & 0.1294 \\
\hline POS & 1.538115 & $0.0222 * * *$ & 1.538115 & $0.0420 * * *$ \\
\hline WEB & 1.196747 & 0.4451 & 1.196747 & 0.4779 \\
\hline R-squared & 0.182234 & & 0.182234 & \\
\hline F-statistic & 9.26583 & & 9.26583 & \\
\hline Prob(F-statistic) & 0.000000 & & 0.000000 & \\
\hline
\end{tabular}

$* * *$ significant at the 0.05 level (2-tailed). 